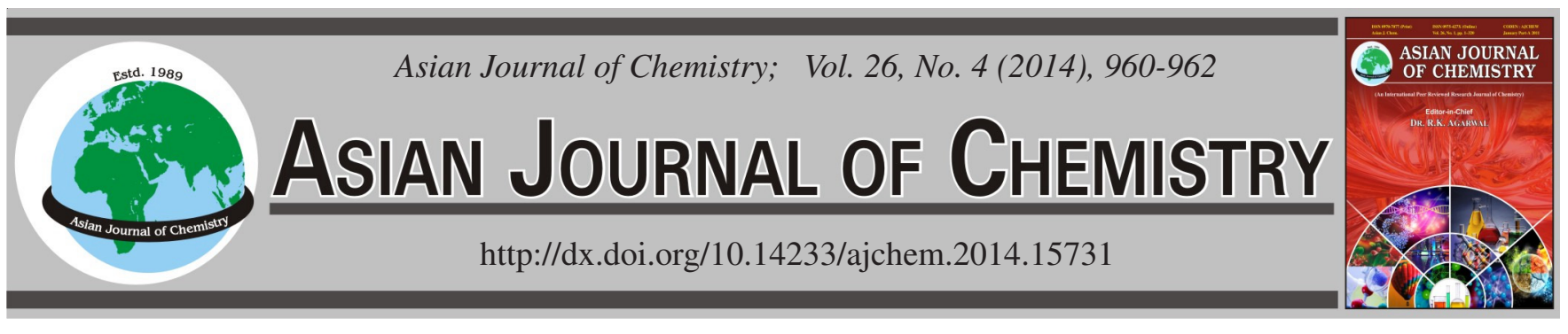

\title{
Vacuum Annealing of White-Light Organic Light-Emitting Devices with Polyfluorene Copolymer as Light-Emitting Layer
}

\author{
Hua WAnG ${ }^{*}$, Yuling Wu, Yang Xu and ZhiXiang GaO
}

Research Center of Advanced Materials Science and Technology, Taiyuan University of Technology, No.79, West Yingze Street, Taiyuan Shanxi 030024, P.R. China

*Corresponding author: Tel/Fax: +86 351 6014852; E-mail: wanghua001@tyut.edu.cn

Received: 4 May 2013;

Accepted: 11 July 2013;

Published online: 15 February 2014;

AJC-14678

White-light organic light-emitting devices (OLEDs) were fabricated, in which poly(9,9-dioctyl)fluorene with insertion of 4,7-bithienyl-
2,1,3-benzothiadiazole (PFO-DBT5) were utilized as light-emitting layer. During fabrication of white-light OLED, PFO-DBT5 films
were vacuum annealed under four different temperatures, respectively. Then, the relationship between vacuum annealing of PFO-DBT5
films and performance of white-light organic light-emitting device was studied by atomic force microscope observation and electrolumi-
nescence properties characterization. It was concluded that degree of stacking order and the inter-chain distance and of PFO-DBT chains
influence device performance directly; the optimal vacuum annealing temperature was gained to be $100{ }^{\circ} \mathrm{C}$ by comparison experiments.

Keywords: White-light, Organic light-emitting device, Annealing, Förster.

ᄂ - - - - - - - - - - - - - - - - - - - - - - - - - - - - -

\section{INTRODUCTION}

White-light organic light-emitting diodes (OLED) can be utilized as full-colour panel display owing to their low energy consumption, light weight and thin thickness. It has acquired remarkable attention for potential application in solid-state lighting. For reducing layers of white-light OLED, developing single-molecule materials as light-emitting layer of while-light OLED has been recent hot topic. Among them, poly $(9,9-$ dioctyl)fluorene (PFO) copolymer is representative one ${ }^{1}$. During fabrication of OLED, PFO copolymer film is usually annealed under vacuum for improving device performance. However, relevant research works are rather scarce, especially for mechanism of vacuum annealing of PFO copolymer film. In present paper, a classical type of PFO copolymer, entitled PFO-DBT5 (Fig. 1) was utilized as light-emitting layer in white-light OLED and relationship between device performance and vacuum annealing of PFO-DBT film was studied.

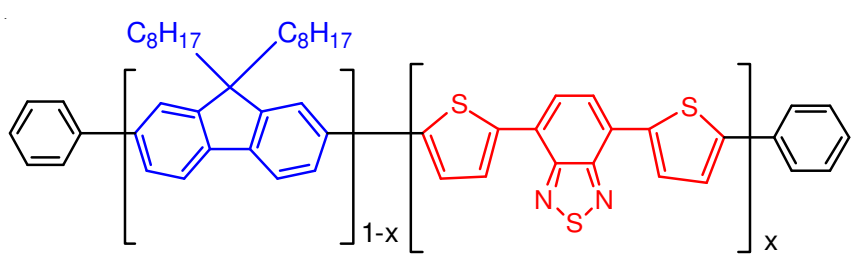

PFO-DBT5: $x=0.0005$

Fig. 1. Chemical formula of PFO-DBT5

\section{EXPERIMENTAL}

PFO-DBT5 was synthesized by Suzuki crossing reaction according to literature method ${ }^{2}$. Four PFO-DBT5 films were prepared by spin-coating using toluene as solvent $(10 \mathrm{mg} / \mathrm{mL})$ and the rotation speeds were $1500 \mathrm{rpm}$. which were annealed under vacuum for $0.5 \mathrm{~h}$ at $80,100,120$ and $140^{\circ} \mathrm{C}$, separately. These films were observed by SPA-300HV atomic force microscope (AFM). The X-ray diffraction (XRD) spectra were measured using Bruker D8 discover analytical X-ray system with $\mathrm{CuK} \alpha$ as radiation $(\lambda=1.54 \AA$ ). Four white-light OLEDs were fabricated with the configuration of ITO/PEDOT:PSS $(50 \mathrm{~nm}) / \mathrm{PFO}-\mathrm{DBT} 5(80 \mathrm{~nm}) / \mathrm{LiF}(1 \mathrm{~nm}) / \mathrm{Ca}(10 \mathrm{~nm}) / \mathrm{Al}(100$ $\mathrm{nm})$, in which PFO-DBT5 films were annealed under vacuum for $0.5 \mathrm{~h}$ at $80,100,120$ and $140{ }^{\circ} \mathrm{C}$, separately. The buffer layer of PEDOT:PSS was spin-coated on precleaned ITO substrate and annealed under vacuum for $0.5 \mathrm{~h}$ at $120{ }^{\circ} \mathrm{C}$. Typically, triple thin layers of $\mathrm{LiF}, \mathrm{Ca}$ and $\mathrm{Al}$ were deposited in a vacuum chamber with a base pressure below $5 \times 10^{-4} \mathrm{~Pa}$. The electroluminescence (EL) performances were characterized with PR-655 spectrometer and Keithley 2400 sourcemeter. All measurements were performed in air at room temperature.

\section{RESULTS AND DISCUSSION}

During luminescence process of PFO-DBT5, PFO at ground state are excited and formed $\mathrm{PFO}^{*}$ at excited state. Then, some PFO* deactivate partly by Förster energy transfer 
(FET) to DBT, which induces red-light emission of DBT. Meanwhile, most $\mathrm{PFO}^{*}$ deactivate by radioactive transition and emit blue-light, which combine with red-light to realize whitelight emission. It can be seen that FET play an important role in luminescence process of PFO-DBT5 and the rate $\left(\mathrm{K}_{\mathrm{DA}}\right)$ of FET from PFO* $^{*}$ to DBT is given by ${ }^{3}$

$$
\mathrm{K}_{\mathrm{DA}}=\frac{2}{3} \mathrm{k}^{2} \tau_{\mathrm{D}}^{-1}\left(\frac{\mathrm{R}_{0}}{\mathrm{R}}\right)^{6}
$$

where, $\mathrm{k}^{2}$ is orientation factor, $\tau_{\mathrm{D}}$ donor decay time of PFO, $\mathrm{R}_{0}$ Förster radius of PFO and R the distance between PFO and DBT. From eqn. 1 , it can be seen that $\mathrm{K}_{\mathrm{DA}}$ is inverse proportional to $\mathrm{R}^{6}$, indicating that $\mathrm{R}$ should be smaller than $\mathrm{R}_{0}$ for high $\mathrm{K}_{\mathrm{DA}}$ of FET in PFO-DBT5. According to literatures, the $\mathrm{R}_{0}$ in PFODBT5 copolymer is $6 \mathrm{~nm}$ approximately ${ }^{4-6}$, which means that $\mathrm{R}$ should be less than $6 \mathrm{~nm}$. The FET in PFO-DBT5 exhibits inter-chain and intra-chain models and the former is major ${ }^{7,8}$. So, the R between PFO of one chain and DBT of adjacent chain influence white-light emission of PFO-DBT5 directly, which can be regarded as inter-chain distance of PFO-DBT5.

Vacuum annealing of PFO-DBT5 films: In PFO-DBT5 film, polymer chains usually twisted and tangled with each other before annealing. Under annealing at $80^{\circ} \mathrm{C}$, the tangled chains got loose and separate, causing generation of big particles and roughness with RMS of $5.92 \mathrm{~nm}$. Under annealing at $100{ }^{\circ} \mathrm{C}$, the PFO-DBT5 chains began to stretch and stack in order, inducing a reduced RMS of $3.83 \mathrm{~nm}$. When annealing temperatures above $120{ }^{\circ} \mathrm{C}$, stretched PFO-DBT5 chains became straight, stacked each other and formed chain clusters, which resulted in increasing roughness again, e.g., RMS of 4.47 and $5.38 \mathrm{~nm}$ for 120 and $140^{\circ} \mathrm{C}$ (Fig. 2).
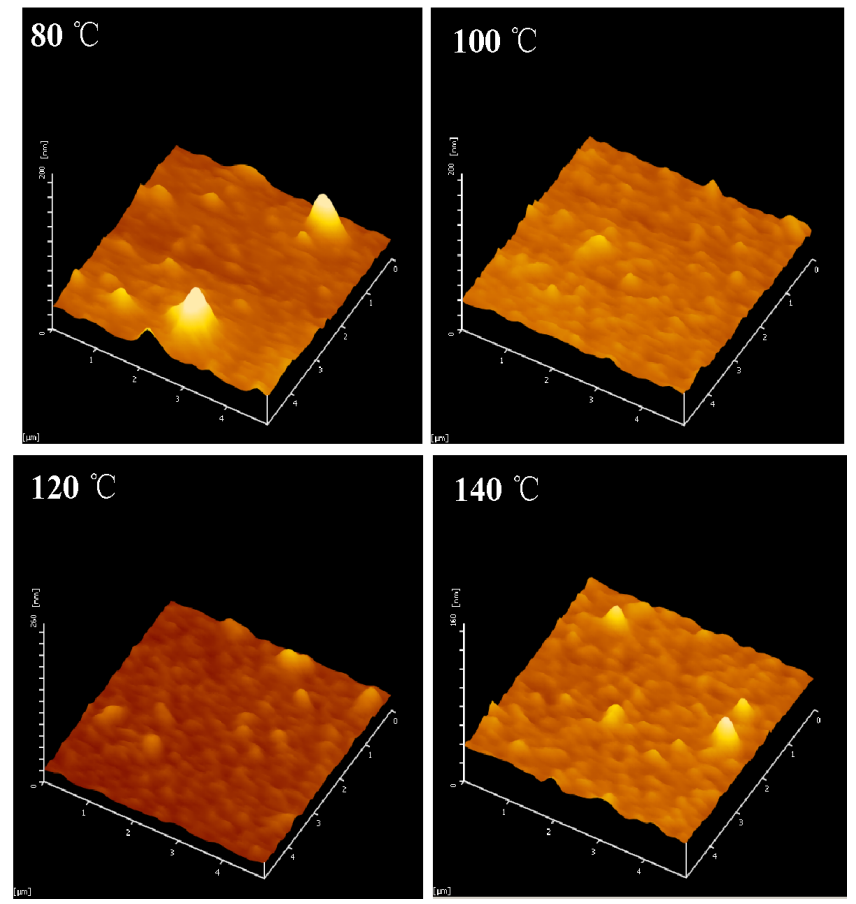

Fig. 2. Series of AFM 3D images $\left(5 \times 5 \mu \mathrm{m}^{2}\right)$ of PFO-DBT5 films

As shown in XRD spectra (Fig. 3), the $80^{\circ} \mathrm{C}$ annealed PFO-DBT5 film had no defined diffraction peaks, suggesting

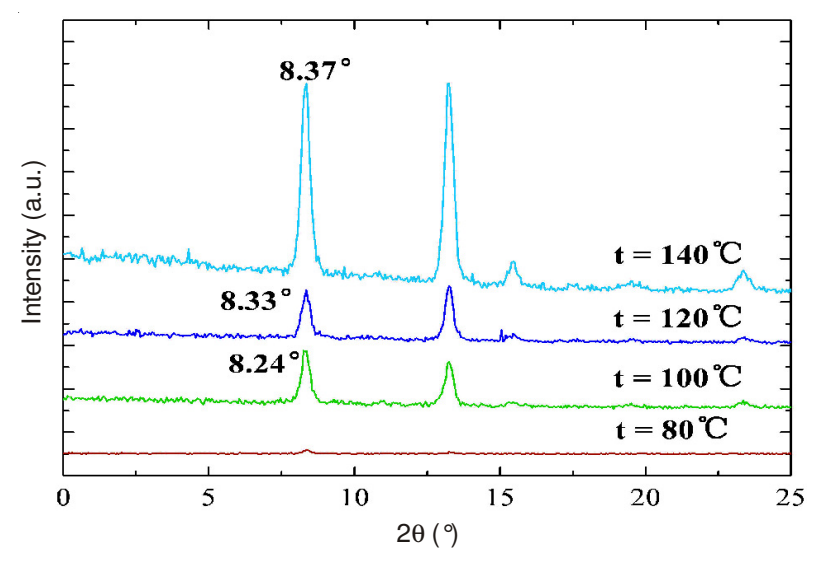

Fig. 3. XRD spectra of PFO-DBT5 films

that PFO-DBT5 chains stacked in disorder. The under annealing temperatures above $100{ }^{\circ} \mathrm{C}$, the films expressed two major diffraction peaks at around $8.3^{\circ}$ and $13.3^{\circ}$; with annealing temperature rising, intensities of these diffraction peaks got stronger and $2 \theta$ of diffraction peaks at around $8.3^{\circ}$ also got smaller slightly meanwhile. Hence, it indicated that heightening annealing temperature of PFO-DBT5 films can enhance degree of order and periodicity of PFO-DBT5 chains stacking and reduce inter-chain distance ${ }^{9}$. Additional, the diffraction peaks at around $8.3^{\circ}$ of all PFO-BDT5 films, corresponding to average inter-chain distance of $1.06 \mathrm{~nm}$ calculated from Bragg diffraction formula, were close to that of the PFO crystalline films oriented parallel to the substrate $e^{10,11}$. And, the peak at $2 \theta \approx$ $13.3^{\circ}$ might correspond to other stacking model of PFO-DBT5 chains, which will be studied in future.

Electroluminescence properties: As mentioned above, the average inter-chain distance of $1.06 \mathrm{~nm}$ in PFO-DBT5 films was much smaller than $\mathrm{R}_{0}$ of $\mathrm{PFO}$, suggesting that high interchain $\mathrm{K}_{\mathrm{DA}}$ of FET from PFO* to DBT. Furthermore, enhancement of degree of stacking order and reduction of inter-chain distance in PFO-DBT5 films following increasing annealing temperatures, which induced higher possibility and bigger $\mathrm{K}_{\mathrm{DA}}$ of inter-chain FET from PFO* to DBT. It resulted in raising ratio of red-light in white-light emission and full width at half maximum (FWHM) of electroluminescence spectra (Fig. 4a). When annealing temperature of PFO-DBT5 film reached $140{ }^{\circ} \mathrm{C}$, the CIE coordinates were $(0.38,0.33)$, close to that of pure white light of $(0.33,0.33)$. In Fig. $4 \mathrm{a}$ and Table-1, it can also be seen that the red-light peaks shift from 580 to $667 \mathrm{~nm}$ when annealing temperatures increased from 80 to $140{ }^{\circ} \mathrm{C}$. It was probably due to enhancement of $\pi$ electron delocalization with increasing degree of stacking order of PFO-DBT5 chains $^{12,13}$. Hence, it was verified that vacuum annealing of PFO-DBT5 film can improve white-light emission of whitelight OLED. However, the luminescence of white-light OLED reduced significantly with heightening of annealing temperatures, as shown in Fig. $4 \mathrm{~b}$. When annealed at $80^{\circ} \mathrm{C}$, PFODBT5 film was electrically broken down at driving voltage of $13 \mathrm{~V}$ due to its high roughness along with big particles. When annealed at 120 and $140^{\circ} \mathrm{C}$, interaction between adjacent PFODBT5 chains became strong, resulting in low luminance and roll-off of current efficiency ${ }^{14}$. So, it was concluded that $100{ }^{\circ} \mathrm{C}$ was the optimal annealing temperature of PFO-DBT5 film. 
TABLE-1

MAIN DATA OF DEVICE PERFORMANCES OF WHITE-LIGHT OLEDS

\begin{tabular}{cccccc}
\hline Temperature $\left({ }^{\circ} \mathrm{C}\right)$ & $\lambda(\mathrm{nm})$ & FWHM $(\mathrm{nm})$ & $\mathrm{CIE}^{\mathrm{a}}$ & Luminance $^{\mathrm{b}}\left(\mathrm{cd} / \mathrm{m}^{2}\right)$ & Maximum current efficiency $(\mathrm{cd} / \mathrm{A})$ \\
\hline 80 & 440,580 & 202 & $(0.39,0.37)$ & - & - \\
100 & 440,630 & 221 & $(0.37,0.36)$ & 4037 & 3.34 \\
120 & 440,635 & 254 & $(0.48,0.39)$ & 1604 & 3.51 \\
140 & 440,667 & 276 & $(0.38,0.33)$ & 178 & 2.92 \\
\hline
\end{tabular}
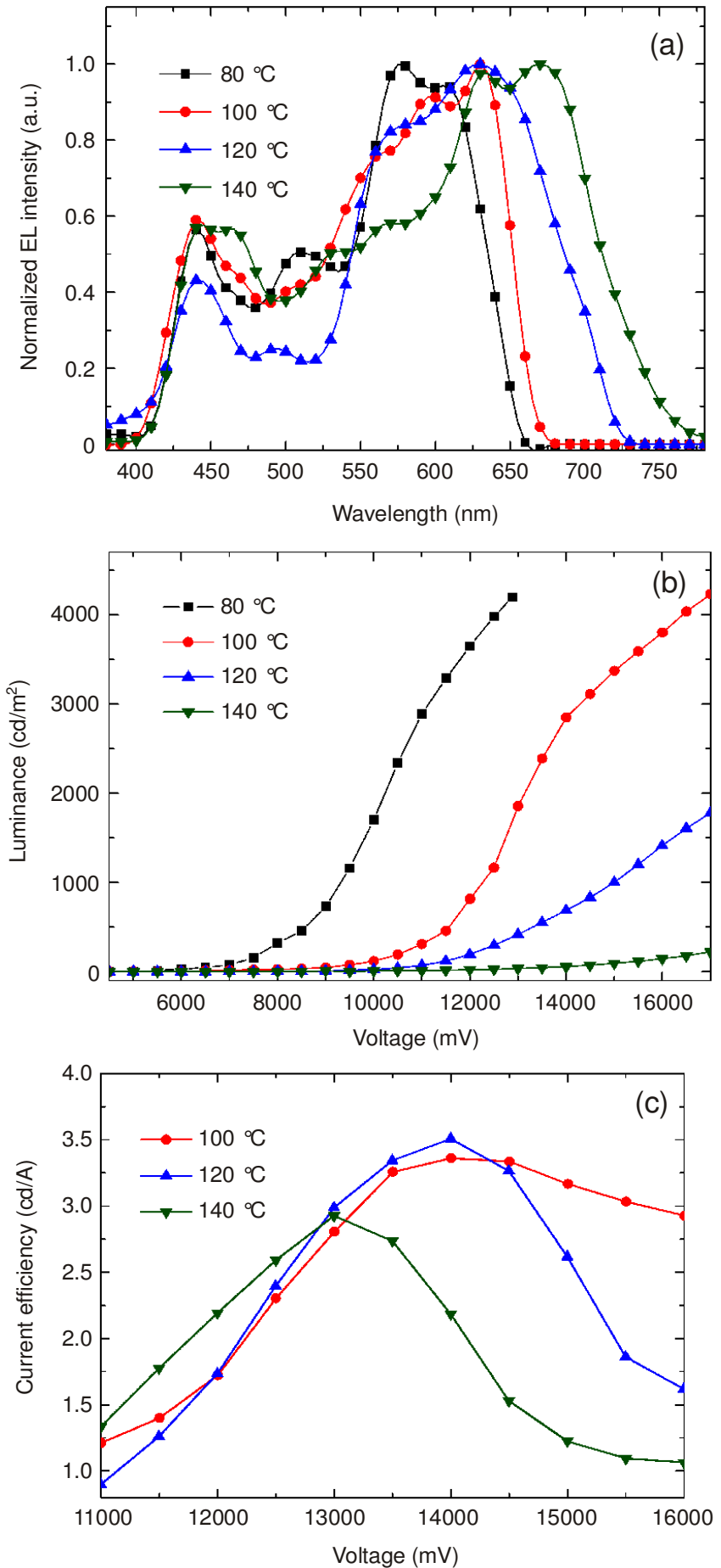

Fig. 4. Electroluminescence spectra (a), voltage-luminance curves (b) and voltage-current efficiency curves (c) of white-light organic lightemitting devices

\section{Conclusion}

Vacuum annealing of PFO-DBT5 film were investigated by AFM and XRD. When PFO-DBT5 was utilized as lightemitting layer in white-light OLED, vacuum annealing temperature would influence device performance. With vacuum annealing temperature rising, the CIE coordinates got closer to that of pure white-light, the luminescence lowered and rolloff of current efficiency got more obvious. By contrast test, the optimized annealing temperature of PFO-DBT5 film was acquired to be $100^{\circ} \mathrm{C}$ during fabrication of white-light OLED. Moreover, it was indicated that varying of degree of stacking order and inter-chain distance in PFO-DBT films by vacuum annealing was the major reason for modification of device performance of white-light OLED.

\section{ACKNOWLEDGEMENTS}

This work was financially supported by International Science \& Technology Cooperation Program of China (2012DFR50460); National Natural Scientific Foundation of China (21071108, 60976018, 21101111, 61274056, 61205179); Shanxi Provincial Key Innovative Research Team in Science and Technology (2012041011); Key Scientific and Technological Project of Shanxi Province (20120321019).

\section{REFERENCES}

1. J.X. Jiang, Y.H. Xu, W. Yang, R. Guan, Z.Q. Liu, H.Y. Zhen and Y. Cao, Adv. Mater., 18, 1769 (2006).

2. Q. Hou, Y.S. Xu, W. Yang, M. Yuan, J.B. Peng and Y. Cao, J. Mater. Chem., 12, 2887 (2002).

3. V. Misra and H. Mishra, J. Phys. Chem. B, 112, 4213 (2008).

4. Y. Kawamura, J. Brooks, J. Brown, H. Sasabe and C. Adachi, Phys. Rev. Lett., 96, 017404 (2006).

5. T. Virgili, D.G. Lidzey and D.D.C. Bradley, Adv. Mater., 12, 58 (2000).

6. B.P. Lyons, K.S. Wong and A.P. Monkman, J. Chem. Phys., 118, 4707 (2003).

7. F.B. Dias, J. Morgado, A.L. Maçanita, F.P. da Costa, H.D. Burrows and A.P. Monkman, Macromolecules, 39, 5854 (2006).

8. D.W. Bright, F. Galbrecht, U. Scherf and A.P. Monkman, Macromolecules, 43, 7860 (2010).

9. M. Knaapila, H.L. Vaughan, T.P.A. Hase, R.C. Evans, R. Stepanyan, M. Torkkeli, H.D. Burrows, U. Scherf and A.P. Monkman, Macromolecules, 43, 299 (2010).

10. R. Verduzco, I. Botiz, D.L. Pickel, S.M. Kilbey II, K.L. Hong, E. Dimasi and S.B. Darling, Macromolecules, 44, 530 (2011).

11. E. Aharon, M. Kalina and G.L. Frey, J. Am. Chem. Soc., 128, 15968 (2006).

12. E. Bundgaard and F.C. Krebs, Macromolecules, 39, 2823 (2006).

13. N. Hundt, K. Palaniappan, J. Servello, D.K. Dei, M.C. Stefan and M.C. Biewer, Org. Lett., 11, 4422 (2009).

14. Z.X. Gao, Y.Y. Hao, H. Wang, Y.Q. Miao and B.S. Xu, Asian J. Chem., 25, 3297 (2013). 